\title{
Comparing Online Cognitive Behavioural Therapy versus Online Positive Psychotherapy, Well-being Theory (PERMA) on Test Anxiety of Online Learning Students: A Randomised Control Study
}

\author{
Fataneh Alibak \\ Morteza Alibak \\ Isfahan University of Technology, Isfahan, Iran
}

\begin{abstract}
This study aims to compare the efficacy of test anxiety interventions using internet-based Cognitive Behavioural Therapy and internet-based positive psychotherapy (PERMA model). Changes in test anxiety responses were evaluated in 48 online postgraduate students who met diagnostic criteria based on DSM-5 and were randomly assigned to three treatment groups: internet-based Cognitive Behavioural Therapy ( $n$ $=16)$, internet-based positive psychotherapy $(n=16)$ and a control group $(n=16)$ over three phases: pretest, post-test and follow-up. Assessments included a self-report questionnaire and a diagnostic interview. An 18-item self-report of the Online Test Anxiety Inventory (OTAI) was used with a high internal consistency $(\alpha=0.91)$ to assess test anxiety of online learning students. The OTAI consists of three factors: online, psychological, and physiological. The analysis of test anxiety by repeated measure ANOVA revealed a significant decrease of anxiety in both treatment groups while no significant change was observed in the control group. The study supports using internet-based psychological interventions for the treatment of test anxiety, which is particularly significant during the COVID-19 restricted teaching environment.
\end{abstract}

\section{Keywords}

Internet-based interventions, Cognitive Behavioural Therapy, Positive psychotherapy (PERMA), test anxiety, online learning students

\section{Introduction}

Test anxiety is a common problem among university students, affecting approximately $40 \%$ of college students (Cassady, 2010). In modern society, test grades and scores play a significant role in an individual's academic and professional opportunities, potentially limiting their educational and vocational development (Zeidner, 2010). Test anxiety is a temporary emotional situation that refers to an individual's disposition to experience heightened worry, interfering and negative thoughts, mental confusion, tension, and physiological reaction in an evaluative situation (Spielberger et al., 1976; Zeidner, 1998).

Although anxiety disorders are among the most common psychological disorders, evidence indicates that these often go untreated (Wang et al., 2007). The reasons for not seeking treatment include existing barriers such as: financial costs, travel time needed to attend face-to-face treatments, fear of being stigmatised and peer rejection (Ebert et al., 2015). Internet-based interventions have been shown to be effective in overcoming some of these limitations (Woods et al., 2017).

Rapid progress in digital technology has influenced all aspects of human life, including education and psychological interventions. Online education enrolments have been growing considerably especially within higher education in the United States (Allen \& Seaman, 2008). In the US, the proportion of students taking at least one online course was $9.6 \%$ in 2002 increasing to $29.7 \%$ in 2015 (Allen \& Seaman, 2017). Despite the continuous growth of online student numbers, a majority of these students do not have adequate computer skills (Saade \& Kira, 2009), which contributes to heightened test anxiety during online examinations (Wang, Newlin, \& Tucker, 2001).

Cognitive Behavioural Therapy (CBT) is a psychological intervention that helps people to change their negative thoughts and maladaptive cognitions in order to modify their problematic behaviour 
and emotional distress (Beck, 1970; Ellis, 1962). The efficacy of CBT has been confirmed by a majority of studies for treatment of a variety of psychological conditions and distress, including anxiety disorders (Hofmann et al., 2012). CBT for test anxiety posits that negative thoughts and worry about the consequences of an exam triggers maladaptive coping behaviour which ultimately leads to the reduction in academic performance (Von Der Embse, Berterian \& Segool, 2013). In the treatment of test anxiety, CBT aims to modify both cognitive distortion and maladaptive behaviour through interventions such as systematic desensitisation, muscle relaxation, cognitive therapy, thought records, and behaviour challenges. However, CBT may not be suitable or beneficial for a significant number of people with anxiety disorders (Barlow, Gorman, Shear, \& Woods, 2000) which require more novel treatment approaches in order to promote durable treatment outcomes and reduced instances of relapse.

Positive Psychology has emerged as a new and growing field with wellbeing identified as a core element of this approach (Seligman \& Csikszentmihalyi, 2000). It emphasises the optimal human functioning rather than a focus on disorders, and promotes those factors that allow individuals, communities, and institutions to thrive (Seligman \& Csikszentmihalyi, 2000). It is rooted in the work of Humanistic psychologists focussing on human potential and strengths such as those outlined by Abraham Maslow (1954) and Carl Rogers (1961). Positive Psychotherapy (PPT) is a therapeutic approach (Seligman, Rashid \& Parks, 2006) based on knowledge and research drawn from Positive Psychology (Seligman, 1998) and aims to address and develop positive attributes including positive emotions. PPT aims to increase happiness and wellbeing rather than merely decrease the symptoms of psychological disorders and treat psychopathology (Rashid, 2008). This approach is consistent with the definition of mental health outlined by the World Health Organization (WHO). Mental health is "a state of well-being in which the individual realises his or her own abilities, can cope with the normal stresses of life, can work productively and fruitfully, and is able to make a contribution to his or her community" (WHO, 2005, p. 5). This definition identifies mental health as more than the absence of mental illness.

Seligman's (2011) well-being theory, based on the acronym PERMA, is a multidimensional construct comprising five measurable elements: Positive emotions refers to the hedonic concept of increasing positive emotions. Engagement involves one's full attention and full immersion, when doing an activity such as meditation exercises. Relationship refers to feeling loved and valued by others. Meaning is defined as working towards a greater purpose beyond one's self. And finally, Accomplishment refers to one's mastery over achieved goals and endeavours (Seligman, 2011).

It is suggested that hedonic (positive feelings) and eudemonic (positive functioning) features of positive wellbeing such as positive emotion, emotional stability, optimism, competence, engagement, meaning, self-esteem, vitality, and resilience are the opposite of symptoms of depression and anxiety (Huppert \& So, 2013; Kern et al., 2015). Consequently, wellbeing is a core element of mental health and it plays a significant role in mental health promotion (Bolier et al., 2013). Various findings indicate that wellbeing plays a protective role against psychopathology such as burnout (Bakker, Demerouti \& Euwema, 2005). Higher levels of wellbeing are negatively associated with daily stressful life events (Cohn, Fredrickson, Brown, Mikels, \& Conway, 2009), and wellbeing is also associated with a healthier life (Diener \& Chan, 2011).

In the past two decades, online and internet-based interventions have drawn attention as a novel method for the treatment of mental disorders. The efficacy and effectiveness of online delivery interventions have been demonstrated by Vella-Brodrick, \& Klein, (2010) as has the meta-analysis conducted by Sander, Rausch, \& Baumeister, (2016). Wanger, Horn, \& Maecker, (2014) demonstrated the equal effectiveness of online and internet-based intervention versus the traditional face-to-face treatments with results in the online group remaining more stable compared to the faceto-face group at the 3-month follow-up phase (Wanger, Horn, \& Maecker, 2014). 
Despite the efficacy of online and internet-based interventions highlighted in previous studies (Sander, Rausch, \& Baumeister, 2016) and the long-term effectiveness of internet delivered therapy compared to face-to-face treatment (Wanger, Horn, \& Maecker, 2014), more studies are needed to compare the impact of different treatments through online and internet-based interventions.

CBT places the emphasis on the maladaptive and negative cognitions of clients and tries to change these distorted cognitions in order to reduce symptoms of mental disorders (Kaczkurkin \& Foa, 2015). While Positive Psychotherapy (PPT) based on PERMA stresses enhancing well-being and therefore reducing the symptoms of mental illnesses including anxiety and depression (Kern et al., 2015).

This study aimed to compare the effectiveness of two different therapy interventions designed to reduce test anxiety, delivered to two treatment groups, compared with a control group, using Zoom and internet-based delivery, to students engaged in online learning.

\section{Method}

\section{Participants}

This study took place at Isfahan University of Technology (IUT) and all subjects were online students enrolled in a postgraduate degree, with $50 \%$ of the sample identifying as female. The mean age of participants was 33.3 years, ranging between $24-48$ years old. All the participants belong to the same ethnic group of Persian people. Forty-eight participants were selected based on their experience of high test anxiety as measured by the Online Test Anxiety Inventory (OTAI) (Alibak, Talebi, \& Neshat-Doost, 2019).

\section{Design}

All participants were assessed at three time points: pre--treatment, post-treatment, and 3 months after post-treatment. Assessments included a self-report questionnaire to identify inclusion criteria (students with high test anxiety) and a 10 to 20 -minute online diagnostic interview for exclusion criteria (see Appendix for details). Only after the diagnostic interview were participants randomly assigned to one of two treatment groups or the control group as follows: group A, the ICBT group (n $=16)$, group $B$, the IPPT group $(n=16)$, group $C$, the control group $(n=16)$. Participants in ICBT \& IPPT received 8 weeks, 1.5 -hour group therapy sessions delivered weekly at time point 1 . Participants in both experimental groups (ICBT \& IPPT) received their treatment interventions weekly via the software (Zoom) by a licensed psychologist, trained in the delivery of both treatment models. The ICBT program involved following modules: Session 1 - understanding of test anxiety, introduction to CBT, and course objectives; Session 2 - cognitive triangle and how thoughts, feelings, and actions are interconnected; Session 3-4 - identifying automatic negative thoughts and cognitive distortions; Session 5-6 - cognitive restructuring; Session 7 - relaxation training; Session 8 - emphasis on continuing practice to relapse prevention (Alibak, Talebi, \& Neshat-Doost, 2018; Heimberg, 2002). The IPPT program consisted of the following modules: Session 1- understanding of test anxiety, introduction to positive psychology, and course objectives; Session 2 - emotions; Session 3 mindfulness and practicing here and now; Session 4-5 - optimism training and explanatory style; Session 6 --positive relationships; Session 7 - resilience training; and Session 8 focussed on continuing practice to relapse prevention (Alibak, Talebi, \& Neshat-Doost, 2018; Seligman, 2006; Seligman et al, 2006; Seligman, 2011; APA, 2012). The use of the Zoom application enabled sharing of screens with participants to display PowerPoint presentations, whiteboards, and videos. Students were asked to $\log$ in at a planned time and at the beginning of each session students' assignments (homework) were reviewed, answering any questions they had, and then new materials were taught. At the end of each session, students had time to ask questions. 
Table 1

Study design

\begin{tabular}{llllll}
\hline Groups & N & $\begin{array}{l}\text { Therapy } \\
\text { received }\end{array}$ & $\begin{array}{l}\text { Treatment } \\
\text { delivery point }\end{array}$ & $\begin{array}{l}\text { Treatment } \\
\text { duration }\end{array}$ & $\begin{array}{l}\text { Measures delivered } \\
\text { Pre/Post/3-month } \\
\text { follow-up }\end{array}$ \\
\hline A & 16 & ICBT & Time point 1 & $\begin{array}{l}1.5 \text { hours per } \\
\text { week 8 weeks }\end{array}$ & Yes \\
\hline B & 16 & IPPT & Time point 1 & $\begin{array}{l}1.5 \text { hours per } \\
\text { week 8 weeks }\end{array}$ & Yes \\
\hline C & 16 & Nil - Wait-listed & Time point 1 & Not applicable & Yes \\
\hline C & 16 & ICBT & Time point 2 & $\begin{array}{l}1.5 \text { hours per } \\
\text { week 8 weeks }\end{array}$ & No \\
\hline
\end{tabular}

Group C was effectively a wait-listed group while groups A and B received the therapy intervention. Group $\mathrm{C}$ participants received the same measures during time point 1 as groups $\mathrm{A}$ and $\mathrm{B}$. In addition, participants allocated to group $\mathrm{C}$ were provided with the ICBT treatment program after the completion of the delivery of the ICBT and IPPT interventions to the two treatment groups. This strategy of delayed delivery of the ICBT intervention to those in the control group allowed all participants to receive either the ICBT or the IPPT intervention thus giving all who participated in the study the benefit of treatment for test anxiety. This design strategy allowed a necessary ethical standard to be respected with no participant denied a treatment experience. The extent to which the delayed delivery of the ICBT interventions might have contributed to the reduction of test anxiety in the control group was neither measured nor factored into our outcome analysis.

\section{Instrument}

The 18-item Online Test Anxiety Inventory (Alibak, Talebi, \& Neshat-Doost, 2019), a self-report measure with a high internal consistency for the total score $(\alpha=0.91)$, was used specifically to assess test anxiety of online learning students. The OTAI consists of three subscales: psychological with 6 items $(\alpha=0.90)$; a physiological dimension with 5 items $(\alpha=0.84)$, and a measure of online (familiarity with computing technology and internet use) with 7 items $(\alpha=0.89)$ (Alibak, Talebi, $\&$ Neshat-Doost, 2019). The psychological dimension measured negative and irrelevant thoughts before and during an exam, such as fear of failure; the physiological dimension measured physical and bodily changes, such as dry mouth, and the online dimension specifically measured test anxiety in the context of online learning and consists of statements that refer to computer literacy, enough knowledge about computer use, dealing with new technology, lack of social interaction (face-to-face interaction) with teaching faculty and other students, etc., which in turn may exacerbate test anxiety for online learning students. By way of example the questions used included: "During my exams, working with computer and the internet make me feel uncomfortable and inefficient.", "Online exams are more stressful for me than traditional face-to-face exams." All items were rated on a 4-point scale ranging from $0=$ almost never, to $3=$ almost always, with a total score ranging from 0 to 54 in which higher scores indicated a higher level of test anxiety. The complete explanation, dimensions, and items of OTAI can be seen in Alibak, Talebi, \& Neshat-Doost, (2019).

\section{Procedure}

Participants were invited to complete the OTAI online with access through the university website. Having completed the OTAI in the pre-test phase, a 10 to 20 -minute online diagnostic interview was scheduled by a Ph.D. licensed psychologist with those students determined to have a high level of test anxiety to be explored further. Exclusion criteria were 1) generalised anxiety disorder and depression symptoms based on the Diagnostic and Statistical Manual of Mental Disorders $5^{\text {th }}$ Edition (DSM-5), 2) high test anxiety already being treated by pharmacological or psychological intervention 
(see Appendix for details). Students diagnosed with depression or generalised anxiety symptoms were excluded and referred to the counselling centre of the IUT to access psychological services. Regarding the two experimental groups (ICBT and IPPT) no participant was adversely affected by the intervention compared to those who did not go through the experiment.

\section{Results}

The means and standard deviations of test anxiety are shown by group and time of measurement in Table 2.

Table 2

Descriptive statistics of anxiety by time

\begin{tabular}{lllll}
\hline \multirow{2}{*}{ IPPT } & & Pre-test & Post-test & Follow-up \\
\cline { 2 - 5 } & Mean & 32.313 & 14.063 & 15.438 \\
\hline \multirow{2}{*}{ ICBT } & Std. Deviation & 7.021 & 3.255 & 3.614 \\
\cline { 2 - 5 } & Mean & 32.668 & 14.750 & 15.688 \\
\hline \multirow{2}{*}{ Control } & Std. Deviation & 8.754 & 1.483 & 2.089 \\
\cline { 2 - 5 } & Mean & 32.000 & 33.313 & 32.500 \\
\hline
\end{tabular}

The effect of culture and other potential confounding variables, including age and gender, were aggregated into the unique error term in the model by the random allocation of samples into the groups.

In Figure 1, the mean of test anxiety is shown for the three different measure points across the three different groups. In the early stage of the study, the mean for each group for test anxiety were approximately the same. This was as expected due to the fact that the groups were homogenous at the beginning. In the control group, no significant change was observed between pre-test, post-test and at 3-month follow-up while a significant decrease was observed in the IPPT and ICBT groups.

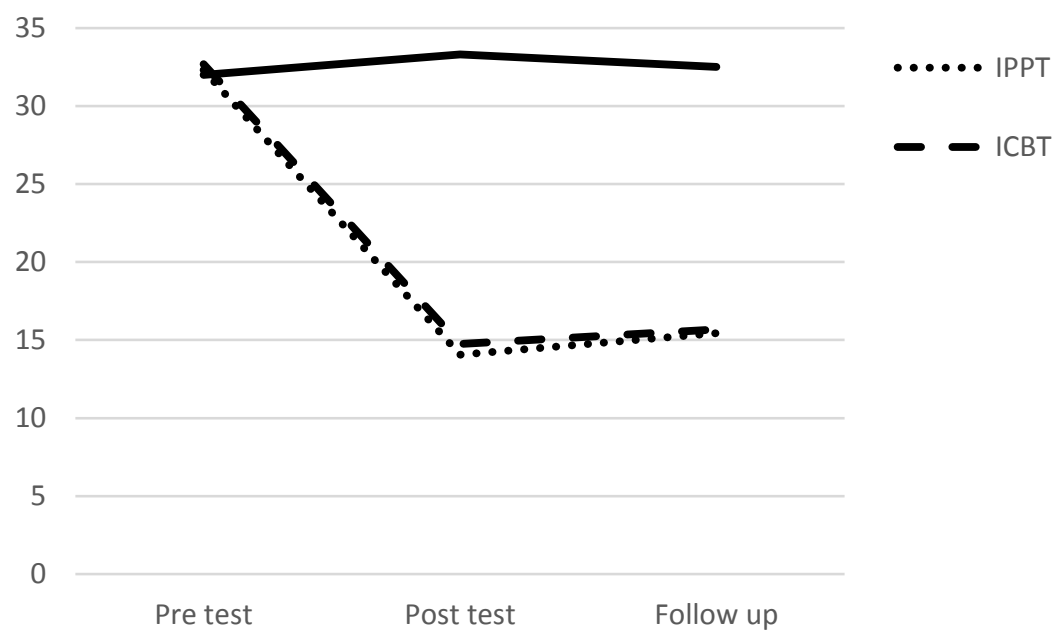

Figure 1: Mean of anxiety by group and time

A repeated measure ANOVA model was utilised to test the statistical hypotheses. The baseline measurement of anxiety and the group membership were considered as the predictors and the post- 
test and follow-up measurements considered as the response variables. Thus, the group with two degrees of freedom indicates the effect of treatment.

Among the presumptions of the model, homogeneity of covariance matrices was evaluated using Box's $M$ test which indicated no significant deviation of this assumption $(F=1.7, \operatorname{Sig}=0.1)$, and the estimations were asymptotically normally distributed for moderate to large sample sizes. The results of the statistical hypothesis testing for the between and within subject effects are presented in Table 3.

Table 3

Tests of between and within subject effects

\begin{tabular}{llllll} 
& Source & F & $\begin{array}{l}\text { Numerator } \\
\text { df }\end{array}$ & $\begin{array}{l}\text { Denominator } \\
\text { df }\end{array}$ & Sig. \\
\hline & Pre-test & 45.861 & 1 & 41 & 0.001 \\
\cline { 2 - 6 } $\begin{array}{l}\text { Between } \\
\text { Subject } \\
\text { Effects }\end{array}$ & Group & 182.515 & 2 & 41 & 0.001 \\
\cline { 2 - 6 } & Sex & 0.000 & 1 & 41 & 0.994 \\
\cline { 2 - 6 } & Group*Sex & 0.113 & 2 & 41 & 0.893 \\
\hline $\begin{array}{l}\text { Within } \\
\text { Subject } \\
\text { Effects }\end{array}$ & Time & 3.394 & 1 & 45 & 0.072 \\
\hline
\end{tabular}

According to Table 3, the effect of treatment is significant at the level of 0.05. In order to compare the three groups, a post hoc test on the marginal scores of post-test anxiety was applied.

As mentioned in Table 4, the marginal anxiety of both IPPT and ICBT groups were significantly different to the control group while no significant difference was observed between IPPT and ICBT groups. Table 3 shows both sex and group*sex were not significant at the level of 0.05 , meaning there was no significant difference in effect of the treatment between males and females. Among the withinsubject effects the main effect of time was not significant while the interaction of group*time was significant at the level of 0.05 . This shows there was a significant difference in the adjusted score for test anxiety between post and follow-up but it was not the same across the groups. However, as seen in Figure 1, this difference was not remarkable.

Table 4

Multiple comparison of adjusted anxiety between groups

\begin{tabular}{llllll}
\hline Parameter & Estimate & Std. Error & df & T & Sig. \\
\hline $\begin{array}{l}\text { IPPT- } \\
\text { CONTROL }\end{array}$ & -17.543 & 1.584 & 44.779 & -11.076 & 0.001 \\
\hline $\begin{array}{l}\text { ICBT- } \\
\text { CONTROL }\end{array}$ & -17.602 & 1.584 & 44.778 & -11.112 & 0.001 \\
\hline IPPT-CBT & 0.059 & 1.584 & 44.778 & 0.037 & 0.970 \\
\hline
\end{tabular}

\section{Discussion}

The main goal of this study was to compare the efficacy of internet-based PPT (IPPT), based on PERMA wellbeing theory, with internet-based CBT (ICBT) for test anxiety within postgraduate students engaged in online education. Through an experimental design with pre-test, post-test, and 
follow up, and by contrasting with the control group, both treatment groups evidenced a significant decrease in their test anxiety. The randomly assigned control group did not receive any treatment during the study and did not show a significant decrease in their test anxiety. The control group were exposed to a complete ICBT treatment protocol (1.5 hours for 8 weeks) after the completion of the study however the impact of this ICBT intervention was not subject to measurement. The findings indicate significant effects for both ICBT and IPPT interventions as treatments for test anxiety symptoms experienced by online students when compared with a control group.

However, in the follow-up phase, a non-significant increase of test anxiety was seen in both experimental groups. This effect may be due to the lack of continuous practice by the college students during the gap between post-test and at 3-month follow-up and the coincidence of the follow-up phase measurement coinciding with final exams. It is possible that this explains a rise of test anxiety among the participants but does not capture any deployment of resilience skills learnt from exposure to either the ICBT or the IPPT interventions as the exam period progressed. It is noted that in this study there was only one follow-up assessment administered at 3 months post intervention, therefore we cannot make conclusions about the long-term benefits of the two experiment groups.

There are multiple approaches to obviate the 'practice effect' that may have occurred due to the readministration of the OTAI. Options include employing well-matched alternative measures, use of tests with multiple similar items, and utilising a randomised clinical trial with a control group (Goldberg, Harvey, Wesnes, Snyder, \& Schneider, 2015). In this current study, a randomised clinical trial with a control group was employed, and the practice effect can be estimated by comparing the repeated measures over time in the control group. However, due to the timing of the final administration of the OTAI this estimation is confounded by the additive stress caused by the finalterm exams. There is a slight, not significant change in the OTAI results noted in the control group $(\mathrm{F}=3.394$, Sig. $=0.072)($ see Table 3$)$.

To the authors' knowledge, no comparison studies between ICBT and IPPT have been performed on test anxiety, however results are in line with previous studies which indicated that internet-delivered CBT (Andersson, 2016; Ebert et al., 2015) and internet-delivered PPT have the potential to reduce anxiety symptoms (Vella-Brodrick, 2010; Mitchell, Stanimirovic, Klein, \& Vella-Brodrick, 2009).

Internet-based delivery of interventions has many advantages for people with limited access to mental health centres, for those who have time restrictions (Rochlen, Zack, \& Speyer, 2004), and for those who prefer not to attend counselling centres physically due to fear of stigmatisation (Cuijpers et al., 2010). Reported benefits also include reduce financial cost and travel time for both clients and clinicians (Christensen et al., 2014). In addition, the effectiveness of internet-delivered interventions for reducing anxiety disorders among adolescents has already been demonstrated (Stjerneklar et al., 2018).

Cognitive Behavioural Therapy, being the most widely used therapy for anxiety disorders (Kaczkurkin, \& Foa, 2015) helps people realise and change distorted, maladaptive, and negative cognitions that negatively influence their behaviour (Kaczkurkin \& Foa, 2015). The CBT approach teaches people how to understand and manage their cognitions, feelings, actions, and behaviours. The Cognitive Behavioural model for test anxiety posits that reductions in catastrophic thinking, (negative cognitions) about exam outcomes can decrease the experience of anxiety symptoms (Craske, 2010).

The results of this study along with previous studies indicate that internet-based CBT (ICBT) interventions show efficacy for the treatment of anxiety symptoms (Romijn et al., 2019; Andrews et al., 2018; Mathiasen et al., 2018; Andersson, 2016).

Positive Psychology interventions, based on wellbeing PERMA approaches, demonstrate negative correlation with depression and anxiety (Kern et al., 2015). According to the Broaden-and-Build Theory (Fredrickson, 2004) positive emotions such as joy, interest, contentment, and love, which are the opposite points of negative emotions such as anxiety, sadness, and anger, can produce optimal 
functioning over the longer term. Negative emotions narrow individuals' attention whereas positive emotions like optimism are associated with broadened attention, thought-action and cognitive flexibility (Fredrickson, 2004). Furthermore, the built-effect of positive emotions develops and increases resilience and coping strategies that further promote positive emotions (Fredrickson, 2004). For example, optimism, which is a form of positive emotion, is an indicator of resilience, and optimistic people are more likely to be resilient and cope with stressful life events (Carver, Scheier \& Segerstrom, 2010).

Mindfulness techniques, applicable to the second component of PERMA (engagement), were applied to increase concentration and decrease test anxiety of university students (Hofmann \& Gomez, 2017). Engagement occurs when someone is fully absorbed in a challenging task, and results in a state called "flow". During flow, deep concentration and intense focus can lead to improved performance (Csikszentmihalyi, 1997; Seligman, 2011) and mindfulness techniques have been shown to increase academic performance (Miralles-Armenteros et al, 2021). Other studies also indicate that mindfulness techniques, such as meditation, enhance a sense of wellbeing, increase focus and improve sleep habits (Goretzki \& Zysk, 2017).

It has been demonstrated that high levels of well-being are associated with positive outcomes, such as positive relationships, effective learning, productivity, creativity, good health, and increased life expectancy (Lyubomirsky et al., 2005; Huppert \& So, 2013) and a positive correlation with academic achievement (Grabel, 2017). Wellbeing has negative correlation with some psychological disorders such as depression and anxiety (Huppert \& So, 2013; Kern et al., 2015).

\section{Conclusion}

This study presents the treatment effects of two interventions, ICBT and IPPT for test anxiety among postgraduate students studying online. Despite differences in treatment models, the findings indicate similarities in the impact of both treatments through the internet. In addition, the overall findings suggest that internet-based interventions, a relatively novel field of research, could be an effective method to reduce test anxiety. Given that postgraduate students most often have access to the internet, online or internet-based psychological interventions provide a much better option than no intervention or treatment avoidance.

Overall, in the COVID-19 pandemic crisis situation it is expected universities' counselling centres support students and provide them online services to keep social distancing and help stop the spread of COVID-19. In addition, conducting such studies add to a growing body of literature focussed on online interventions essential for consideration during key times such as the COVID-19 pandemic crisis.

\section{Acknowledgments}

We would like to thank the director and staff of the E-learning Centre and Counselling Centre of Isfahan University of Technology, for their help and constant support during the course of this project. 


\section{References}

Alibak, M., Talebi, H., \& Neshat-Doost, H. T. (2019). Development and validation of a test anxiety inventory for online learning students. Journal of Educators Online, 16(2).

Alibak, M., Talebi, H., \& Neshat-Doost, H. T. (2018). Study of test anxiety of online education and comparison of the effects of three web-based therapies: Positive Psychotherapy based on Wellbeing theory, Acceptance and Commitment Therapy, and Cognitive Behavioural Therapy (Unpublished doctoral dissertation). University of Isfahan, Isfahan, Iran.

Allen, I. E., \& Seaman, J. (2008). Staying the course: Online education in the United States, 2008. Sloan Consortium.

Allen, I. E., \& Seaman, J. (2017). Digital compass learning: Distance education enrolment report 2017. Babson Survey Research Group.

Andersson, G. (2016). Internet-delivered psychological treatments. Annual Review of Clinical Psychology, 12, 157-179.

Andrews, G., Basu, A., Cuijpers, P., Craske, M. G., McEvoy, P., English, C. L., \& Newby, J. M. (2018). Computer therapy for the anxiety and depression disorders is effective, acceptable and practical health care: an updated meta-analysis. Journal of Anxiety Disorders, 55, 70-78.

American Psychological Association (2012). APA's road to resilience brochure. Retrieved from https://www.acesconnection.com/g/embracing-aces-in-lexington-ky/blog/apa-s-road-to-resilience-brochure

Bakker, A. B., Demerouti, E., \& Euwema, M. C. (2005). Job resources buffer the impact of job demands on burnout. Journal of Occupational Health Psychology, 10, 170-180.

Barlow, D. H., Gorman, J. M., Shear, M. K., \& Woods, S. W. (2000). Cognitive-behavioral therapy, imipramine, or their combination for panic disorder: A randomized controlled trial. Jama, 283(19), 2529-2536.

Beck, A. T. (1970). Cognitive therapy: Nature and relation to behavior therapy. Behavior therapy, 1(2), 184-200.

Bolier, L., Haverman, M., Westerhof, G. J., Riper, H., Smit, F., \& Bohlmeijer, E. (2013). Positive psychology interventions: a meta-analysis of randomized controlled studies. BMC Public Health, 13(1), 119.

Carver, C. S., Scheier, M. F., \& Segerstrom, S. C. (2010). Optimism. Clinical Psychological Review, 30.

Cassady, J. C. (2010). Test anxiety: Contemporary theories and implications for learning. Anxiety in Schools: The Causes, Consequences, and Solutions for Academic Anxieties, 7-26.

Christensen, H., Batterham, P., Mackinnon, A., Griffiths, K. M., Hehir, K. K., Kenardy, J., . \& Bennett, K. (2014). Prevention of generalized anxiety disorder using a web intervention, iChill: randomized controlled trial. Journal of Medical Internet Research, 16(9), e199.

Cohn, M.A., Fredrickson, B.L., Brown S.L, Mikels J. A., \& Conway A.M. (2009). Happiness unpacked: Positive emotions increase life satisfaction by building resilience. Emotion, 9, 361-368.

Craske, M. G. (2010). Cognitive-behavioral therapy. American Psychological Association.

Csikszentmihalyi, M. (1997). Flow and the psychology of discovery and invention. HarperPerennial, New York, 39.

Csikszentmihalyi, M. (1997). Flow and education. NAMTA Journal, 22(2), 2-35.

Cuijpers, P., van Straten, A., Warmerdam, L., \& van Rooy, M. J. (2010). Recruiting participants for interventions to prevent the onset of depressive disorders: Possibile ways to increase participation rates. BMC Health Services Research, 10(1), 1-6.

Diener E., \& Chan M.Y. (2011): Happy people live longer: Subjective well-being contributes to health and longevity. Applied Psychology: Health and Well-being 2011, 3: 1-43.

Ebert, D. D., Zarski, A. C., Christensen, H., Stikkelbroek, Y., Cuijpers, P., Berking, M., \& Riper, H. (2015). Internet and computer-based cognitive behavioral therapy for anxiety and depression in youth: a meta-analysis of randomized controlled outcome trials. PloS One, 10(3), e0119895.

Edition, F. (2013). Diagnostic and statistical manual of mental disorders. American Psychiatric Association, 21.

Ellis, A. (1962). Reason and emotion in psychotherapy. New York: Lyle Stuart.

Fredrickson, B. L. (2004). The broaden-and-build theory of positive emotions. Philosophical Transactions of the Royal Society of London. Series B: Biological Sciences, 359(1449), 1367-1377. 
Goldberg, T. E., Harvey, P. D., Wesnes, K. A., Snyder, P. J., \& Schneider, L. S. (2015). Practice effects due to serial cognitive assessment: implications for preclinical Alzheimer's disease randomized controlled trials. Alzheimer's \& Dementia: Diagnosis, Assessment \& Disease Monitoring, 1(1), 103-111.

Goretzki, M., \& Zysk, A. (2017). Using mindfulness techniques to improve student wellbeing and academic performance for university students: A pilot study. Journal of the Australian and New Zealand Student Services Association, 25(1), 1336.

Gräbel, B. F. (2017). The relationship between wellbeing and academic achievement: A systematic review (Master's thesis, University of Twente).

Heimberg, R. G. (2002). Cognitive-behavioral therapy for social anxiety disorder: current status and future directions. Biological Psychiatry, 51(1), 101-108.

Hofmann, S. G., Asnaani, A., Vonk, I. J., Sawyer, A. T., \& Fang, A. (2012). The efficacy of cognitive behavioral therapy: A review of meta-analyses. Cognitive Therapy and Research, 36(5), 427-440.

Hofmann, S. G., \& Gómez, A. F. (2017). Mindfulness-based interventions for anxiety and depression. Psychiatric Clinics, 40(4), 739-749.

Huppert, F. A., \& So, T. T. (2013). Flourishing across Europe: Application of a new conceptual framework for defining well-being. Social indicators research, 110(3), 837-861.

Kaczkurkin, A. N., \& Foa, E. B. (2015). Cognitive-behavioral therapy for anxiety disorders: an update on the empirical evidence. Dialogues in Clinical Neuroscience, 17(3), 337.

Kern, M. L., Waters, L. E., Adler, A., \& White, M. A. (2015). A multidimensional approach to measuring well-being in students: Application of the PERMA framework. The Journal of Positive Psychology, 10(3), 262-271.

Lyubomirsky, S., King, L., \& Diener, E. (2005). The benefits of frequent positive affect: Does happiness lead to success? Psychological Bulletin, 131(6), 803.

Maslow, A. (1954). Motivation and personality. New York, NY: Harper \& Row.

Mathiasen, K., Riper, H., Andersen, T. E., \& Roessler, K. K. (2018). Guided internet-based cognitive behavioral therapy for adult depression and anxiety in routine secondary care: observational study. Journal of Medical Internet Research, 20(11), e10927.

Miralles-Armenteros, S., Chiva-Gómez, R., Rodríguez-Sánchez, A., \& Barghouti, Z. (2021). Mindfulness and academic performance: The role of compassion and engagement. Innovations in Education and Teaching International, 58(1), 3-13.

Mitchell, J., Stanimirovic, R., Klein, B., \& Vella-Brodrick, D. (2009). A randomised controlled trial of a self-guided internet intervention promoting well-being. Computers in Human Behavior, 25(3), 749-760.

Rashid, T. (2008). Positive psychotherapy Positive psychology: Exploring the best in people. In J. Lopez Shane, (Ed.) Pursuing human flourishing (Vol. 4, pp. 188-217). Westport, CT: Praeger

Rochlen, A. B., Zack, J. S., \& Speyer, C. (2004). Online therapy: Review of relevant definitions, debates, and current empirical support. Journal of Clinical Psychology, 60(3), 269-283.

Rogers, C. (1961). On becoming a person: A therapist's view of psychotherapy. London, England: Constable.

Romijn, G., Batelaan, N., Kok, R., Koning, J., van Balkom, A., Titov, N., \& Riper, H. (2019). Internet-Delivered Cognitive Behavioral Therapy for Anxiety Disorders in Open Community Versus Clinical Service Recruitment: Meta-Analysis. Journal of Medical Internet Research, 21(4), e11706.

Saade, R., \& Kira, D. (2009). Computer anxiety in e-learning: The effect of computer self-efficacy. Journal of Information Technology Education, 8, 177-191.

Sander, L., Rausch, L., \& Baumeister, H. (2016). Effectiveness of internet-based interventions for the prevention of mental disorders: a systematic review and meta-analysis. JMIR Mental Health, 3(3), e38.

Seligman, M. E., \& Csikszentmihalyi, M. (2000). Positive psychology: An introduction (Vol. 55, No. 1, p. 5). American Psychological Association.

Seligman, M. E. (1998). Building human strength: Psychology's forgotten mission. APA Monitor, January 2.

Seligman, M. E., Rashid, T., \& Parks, A. C. (2006). Positive psychotherapy. American Psychologist, 61 (8), 774.

Seligman, M. E. (2006). Learned optimism: How to change your mind and your life. Vintage. 
Seligman, M. E. (2011). Flourish: a visionary new understanding of happiness and well-being. Policy, 27(3), 60-1.

Spielberger, C. D., Anton, W. D., \& Bedell, J. (1976). The nature and treatment of test anxiety. In M. Zuckerman \& C. D. Spielberger (Eds.), Emotions and anxiety: New concepts, methods, and applications (pp. 317-344). Hillsdale, NJ: Erlbaum.

Stjerneklar, S., Hougaard, E., Nielsen, A. D., Gaardsvig, M. M., \& Thastum, M. (2018). Internet-based cognitive behavioral therapy for adolescents with anxiety disorders: A feasibility study. Internet Interventions, 11, 30-40.

Vella-Brodrick, D., \& Klein, B. (2010). Positive psychology and the internet: A mental health opportunity. Electronic Journal of Applied Psychology, 6(2), 30-41.

Von Der Embse, N., Barterian, J., \& Segool, N. (2013). Test anxiety interventions for children and adolescents: a systematic review of treatment studies from 2000-2010. Psychology in the Schools, 50(1), 55-71. doi:10.1002/pits.21660.

Wang, P. S., Aguilar-Gaxiola, S., Alonso, J., Angermeyer, M. C., Borges, G., Bromet, E. J., . \& Haro, J. M. (2007). Use of mental health services for anxiety, mood, and substance disorders in 17 countries in the WHO world mental health surveys. The Lancet, 370(9590), 841-850.

Wang, A., Newlin, M., \& Tucker, T. (2001). A discourse analysis of online classroom chats: Predictors of cyber-student performance. Teaching of Psychology, 28(3), 222-226. doi:10.1207/S15328023TOP2803_09.

Wagner, B., Horn, A. B., \& Maercker, A. (2014). Internet-based versus face-to-face cognitive-behavioral intervention for depression: a randomized controlled non-inferiority trial. Journal of Affective Disorders, 152, 113-121.

Woods, A. P., Stults, C. B., Terry, R. L., \& Rego, S. A. (2017). Strengths and Limitations of Internet-Based CognitiveBehavioral Treatments for Anxiety Disorders. Pragmatic Case Studies in Psychotherapy, 13(3), 271-283.

World Health Organization. Department of Mental Health and Substance Dependence, Noncommunicable Diseases and Mental Health, World Health Organization, Geneva (2003). (c) World Health Organization 2003.

Zeidner, M. (1998). Test anxiety: The state of the art. New York, NY: Plenum Press.

Zeidner, M., \& Mathews, G. (2010). Anxiety 101. New York, NY: Springer Publishing Company.

The authors may be contacted via

f.alibak@dralibak.ir

m.alibak@dralibak.ir

Please cite this paper as:

Alibak, F., \& Alibak, M. (2021). Comparing online cognitive behavioural therapy versus online positive psychotherapy, well-being theory (PERMA) on test anxiety of online learning students: A randomised control study. Journal of the Australian and New Zealand Student Services Association, 29(1), 6-17. https://doi.org.10.30688/janzssa.2021.1.08 


\section{Appendix I}

The diagnostic interview was administered by three licensed psychologists at the appointment time scheduled for each participant. The following are the questions.

1-Have you ever been treated for anxiety? When and was the treatment effective?

2-Are you currently being treated for anxiety (pharmacological or psychological)?

\section{Depression Questions}

1. Do you have low mood constantly (e.g., feels sad, empty, and hopeless)?

2. Do you get pleasure from activities that you used to enjoy?

3. Can you concentrate on anything for very long?

4. Do you feel worthless nearly every day?

5. Do you feel unhappy and sad compared to other people?

6. Do you feel fatigue or loss of energy nearly every day?

7. Do you sleep less or more than usual every day?

8. Do you feel change in your appetite?

9. Do you have suicidal thoughts or think about death recurrently?

\section{Generalised Anxiety Questions}

1. Do you feel nervous, anxious or on edge most often?

2. Are you able to stop or control worrying?

3. Do you worry too much about different things every day?

4. Do you often get easily fatigued?

5. Are you so restless that it is hard for you to sit still?

6. Do you get easily annoyed or irritated very often?

7. Do you usually feel afraid as if something awful might happen?

Students diagnosed with depression or generalised anxiety symptoms were excluded and referred to the counselling centre of the IUT to access psychological services. 